\title{
Original Article (short paper) \\ Effect of educational training on nutrition and weight control in under-18 Spanish wrestlers
}

\author{
Andrea Visiedo \\ Universidad de Murcia, Murcia, España \\ Jose Manuel Palao \\ University of Wisconsin, Parkside, EU
}

\begin{abstract}
The aim of this study was to investigate the effect of a formative program concerning nutrition, weight control, and its risks wrestlers under the age of 18 (under-18) at the Spanish national level. The sample comprised 36 under-18 wrestlers that were pre-selected for the Spanish national team. A quasi-experimental design with a pre-test and post-test was used. The dependent variables were the knowledge of nutrition and weight control and its risks. The independent variable was the educational program. The program had three 30-minute sessions that combined talks, videos, and tasks to complete. Descriptive and inferential analyses were done (t-test, Wilcoxon test). Results indicate that the educational program was effective at increasing under-18 wrestlers' knowledge about weight control and its risks, but was ineffective with regard to nutrition knowledge. The paper concludes with a discussion regarding the effect of the intervention program, the difficulties with including this type of knowledge and skill in the preparation of combat sport athletes, and the need for further research in this area.
\end{abstract}

Keywords: combat sport, performance, prevention, knowledge

\section{Introduction}

In peak performance sport, the goal is to achieve the highest possible success. The intense schedules of practice and competition are not always good for the health of the athletes. Ideally, the training process should strike a balance between performance and the athletes' wellness. Most of the actions performed by the players are influenced by the sport's regulation. In wrestling, athletes compete in different categories depending upon their weight; therefore, they can compete with athletes of similar characteristics. However, weight control to compete in a specific weight category can result in the use of unhealthy measures before competition, which can put the athletes' health at risk ${ }^{1,2}$. Wrestlers change their weight 4-10 times per year, and this pattern is followed by athletes even younger than 15 years of age ${ }^{1}$.

Most wrestlers have body weights that are above their competition weights in the practice periods of the season. In the weight control process, the most prevalent nutritional strategy is the reduction of or abstention from fluid intake or certain foods. This process is sometimes complemented with saunas, heated rooms, or practicing in a neoprene suit ${ }^{1,3-5}$. After weigh-in for competition, wrestlers take in high amounts of food and liquids, gaining an excessive amount of weight ${ }^{4}$. This pattern is part of the culture of this sport, and there is pressure surrounding the athletes, who see this type of weight control as normal and part of the preparation process.

These situations, created by a lack of knowledge or a poor use of it, are putting athletes' health at risk. The wrestlers' behaviors are detrimental due to the amount of weight lost, the time in which wrestlers lose the weight, or the amount and frequency of the weight loss episodes ${ }^{1,6}$. Weight control emphasizes the problem of continually comparing oneself with other athletes and individuals, often involving the use of inadequate measures ${ }^{4,7,8}$. The process of quick weight loss followed by a rapid weight recovery is known as "weight cycling," and it can affect the athlete physically and psychologically. The combination of inadequate meals, long practice duration, stress, and the desire to change his or her weight could result in an eating disorder ${ }^{9,10}$.

In wrestling, there is a long history of debate and concern about the appropriateness of certain weight loss practices ${ }^{1,4,11-13}$. The death of three American college wrestlers in 1997 prompted the National Collegiate Athletic Association (NCAA) to forbid the use of weight control methods that could have a negative effect on wrestlers' health. However, studies show that $40 \%-60 \%$ of the athletes still use these methods ${ }^{7,14}$.

A lack of adequate and accurate information by wrestlers, coaches, and parents could be one of the causes for these situations ${ }^{11,15}$. Prevention and education is considered a key aspect in reducing or avoiding the risk of these situations. However, educational programs must have the support or involvement of coaches and families to be effective $\mathrm{e}^{5,15-19}$. In fact, available information has shown that they are effective in increasing athletes' knowledge and self-efficacy ${ }^{16,18}$, reducing the intentions to use inadequate methods ${ }^{15,21}$, improving the quality of the athletes' intake $e^{5,22}$, and that athletes support their use ${ }^{16,19}$. In the current literature, no studies were found concerning formative programs that combine nutrition and weight control in combat sports. Additionally, most of the studies concerning weight management and sport were conducted with female athletes ${ }^{5,15,16,19,23,24,25}$. The aim of this study was to assess the effect of a formative program involving nutritional education and weight control and its risks in under-18 wrestlers at the Spanish national level. 


\section{Methods}

The sample comprised 36 under- 18 wrestlers that were preselected for the Spanish national wrestling team and the head coaches of the under-18 Spanish male and female teams( 33.00 \pm 3.6 years of age and $6.00 \pm 1.41$ years of experience). The characteristics of the sample are described in Table 1. The study was approved by the Spanish National Wrestling Federation and the Ethical Committee of the University of Murcia. Participation in the study was voluntary. All participants were informed about the procedures of the study and were required to sign an informed consent before the study began.

A quasi-experimental design with a pre-test and post-test was conducted. The dependent variables were the knowledge of nutrition and weight control and its risks. The independent variable was the educational program. The athlete's knowledge was measured using an ad-hoc questionnaire. Coaches' and wrestlers' perception, level of satisfaction, and fulfillment of the task during the sessions were registered using questionnaires and interviews. The program involved three 30 -minute sessions, which combined talks, videos, and tasks to complete.

The questionnaire and the training were designed using manuals concerning the topic ${ }^{19,26}$. The questionnaire assessed the basic knowledge of nutrition and weight control and its risk. The questionnaire consisted of 35 true-false questions (23 questions about nutrition knowledge and 12 about weight control and its risks). The questionnaire and the training that was completed were validated by experts (content validity), and were approved by the Technical Director of the Spanish National Wrestling Federation. Experts were asked to evaluate the qualitative (open questions) and quantitative (on a scale from 1 to 10) questions from the questionnaire and the training regarding the following: degree of understanding, degree of adequacy, and the need to reduce or include more questions or information. Following Bulger and Housner ${ }^{27}$, questions with values lower than 7.0 were eliminated, questions with values between 7.1 and 8.0 were modified, and questions with values higher than 8.1 were accepted or accepted with modifications. The reliability of the questionnaire was established using a test-retest protocol with 12 wrestlers (average age $24.16 \pm 4.87$ years, national level competition). The reliability of each item was calculated using the Kappa Index for each of the questions using the SPSS software. The lowest value of the questions was 0.615 .

Table 1. Characteristics of sample (wrestlers).

\begin{tabular}{lcccccc}
\hline & \multicolumn{2}{c}{ Age (yr) } & \multicolumn{2}{c}{ Height (m) } & \multicolumn{2}{c}{ Weight (kg) } \\
\cline { 2 - 7 } & M & SD & M & SD & M & SD \\
\hline Gender & & & & & & \\
Female (n=8) & 17.11 & 2.09 & 1.67 & 0.09 & 63.1 & 9.94 \\
Male (n=28) & 17.59 & 1.74 & 1.74 & 0.07 & 68.06 & 14.3 \\
\hline Age group & & & & & & \\
Under-18 (n=23) & 19.0 & 1.23 & 1.73 & 0.08 & 69.00 & 14.59 \\
Under-15 (n=13) & 16.0 & 0.66 & 1.70 & 0.09 & 53.76 & 26.19 \\
\hline Modality & & & & & & \\
Greco-Roman (n=15) & 17.59 & 1.67 & 1.75 & 0.07 & 70.33 & 16.08 \\
Freestyle (n=21) & 17.41 & 1.9 & 1.70 & 0.08 & 65.00 & 11.39 \\
\hline
\end{tabular}

The educational program comprised three 30-minute sessions, which combined talks, videos, and tasks to complete. The goal of the intervention program was to provide knowledge about nutrition and weight control and its risks. The sessions were integrated into the training schedule of the under-18 national team. The wrestlers were divided into two groups (Greco-Roman and Freestyle). Each session was divided into two blocks of 15 minutes. The first 15 -minute block was theoretical, and the second 15 -minute block was practical (tasks). Table 2 shows the distribution of the contents in the sessions. The sessions were directed by one of the researchers, who is a former wrestler at the national level and a registered dietician. At the end of each session, a survey composed of five closed questions was administered to the wrestlers to measure the level of acquisition of the knowledge and their opinion of the session. The questionnaire that measured the knowledge was completed before and after the intervention program. After the three sessions were completed, interviews were conducted with the athletes' coaches regarding the educational program. Descriptive and inferential analyses of the results (average, standard deviation, percentages, t-test for evidence of relationship, and Wilcoxon test were performed using SPSS software. The level of significance was set at $p<.05$.

Table 2. Content distribution in the sessions of the educational program.

\begin{tabular}{|c|c|c|c|c|}
\hline Session & Time & Topic & Content & Task \\
\hline 1 & $\begin{array}{l}30 \\
\min \end{array}$ & $\begin{array}{l}\text { Basic nutrition } \\
\text { knowledge }\end{array}$ & $\begin{array}{l}\text { Diet control, } \\
\text { nutrition } \\
\text { substrates, and } \\
\text { hydration }\end{array}$ & $\begin{array}{l}\text { Classify food } \\
\text { and organize } \\
\text { food plate }\end{array}$ \\
\hline 2 & $\begin{array}{l}30 \\
\min \end{array}$ & $\begin{array}{l}\text { Weight control } \\
\text { and eating } \\
\text { habits }\end{array}$ & $\begin{array}{l}\text { Diet planning } \\
\text { and moments } \\
\text { of the season }\end{array}$ & $\begin{array}{l}\text { Diet evaluation } \\
\text { and adaptations }\end{array}$ \\
\hline 3 & $\begin{array}{l}30 \\
\min \end{array}$ & $\begin{array}{l}\text { Weight control } \\
\text { risk }\end{array}$ & $\begin{array}{l}\text { Poor diet, } \\
\text { negative effect } \\
\text { of weight con- } \\
\text { trol, myths }\end{array}$ & $\begin{array}{c}\text { Problem } \\
\text { solving (risky } \\
\text { situations and } \\
\text { solutions) }\end{array}$ \\
\hline
\end{tabular}

\section{Results}

Prior to the educational program, the wrestlers' knowledge was satisfactory regarding nutrition $(>70 \%$ ) (Table 3 ). Male wrestlers had significantly more nutrition knowledge than female wrestlers. Regarding the effect of the program, the results showed a significant reduction in knowledge of nutrition (19\%) and an increase in knowledge about weight control and its risks $(20 \%)$. For females, this change in nutrition knowledge was not significant.

Prior to the educational program, the wrestlers' knowledge was adequate regarding weight control and its risks $(\sim 50 \%)$ (Table 4). No significant differences were found with regard to gender, age group, or modality. Regarding the knowledge of weight control, the results showed a significant increase in knowledge of weight control and its risks after the program $(20 \%)$. The level of player satisfaction with the program and the application of the sessions are shown in Table 5. 
Table 3. Wrestlers' knowledge of nutrition before and after the educational training

\begin{tabular}{|c|c|c|c|c|c|c|c|c|}
\hline & \multicolumn{4}{|c|}{ Pre-test } & \multicolumn{4}{|c|}{ Post-test } \\
\hline & \multicolumn{2}{|c|}{$\begin{array}{c}\text { Scale } \\
(0 \text { to 23) }\end{array}$} & \multicolumn{2}{|c|}{ Percentage } & \multicolumn{2}{|c|}{$\begin{array}{c}\text { Scale } \\
(0 \text { to 23) }\end{array}$} & \multicolumn{2}{|c|}{ Percentage } \\
\hline & $\mathbf{X}$ & SD & $\mathbf{X}$ & SD & $\mathbf{X}$ & SD & $\mathbf{X}$ & SD \\
\hline \multicolumn{9}{|l|}{ Gender } \\
\hline $\begin{array}{l}\text { Female } \\
(\mathrm{n}=8)\end{array}$ & 15.50 & 4.27 & 67.63 & 18.58 & 14.44 & 1.87 & 55.07 & 8.13 \\
\hline $\begin{array}{l}\text { Male } \\
(\mathrm{n}=28)\end{array}$ & 17.48 & 2.17 & 76.00 & 9.21 & $14.29 *$ & 1.58 & 54.75 & 6.52 \\
\hline \multicolumn{9}{|l|}{ Age group } \\
\hline $\begin{array}{l}\text { Under-18 } \\
(n=23)\end{array}$ & 17.34 & 3.06 & 75.42 & 13.34 & $13.95^{*}$ & 1.27 & 54.25 & 5.54 \\
\hline $\begin{array}{l}\text { Under-15 } \\
(n=13)\end{array}$ & 16.38 & 2.46 & 71.23 & 10.72 & $14.23 *$ & 2.03 & 55.85 & 8.84 \\
\hline \multicolumn{9}{|l|}{ Modality } \\
\hline $\begin{array}{l}\text { Greco- } \\
\text { Roman } \\
(\mathrm{n}=15)\end{array}$ & 17.16 & 3.21 & 74.63 & 13.97 & $14.66^{*}$ & 1.33 & 55.79 & 5.81 \\
\hline $\begin{array}{l}\text { Freestyle } \\
(\mathrm{n}=21)\end{array}$ & 16.91 & 2.49 & 73.55 & 11.95 & $14.30^{*}$ & 1.69 & 54.34 & 7.36 \\
\hline Total & 16.79 & 2.86 & 73.91 & 12.5 & 14.31 & 1.57 & 54.83 & 6.83 \\
\hline
\end{tabular}

Legend: $p<.05$, indicates significant differences between the pre-test and the post-test.

Table 4. Wrestlers' knowledge of weight control before and after the educational training

\begin{tabular}{|c|c|c|c|c|c|c|c|c|}
\hline & \multicolumn{4}{|c|}{ Pre-test } & \multicolumn{4}{|c|}{ Post-test } \\
\hline & \multicolumn{2}{|c|}{$\begin{array}{c}\text { Scale } \\
(0 \text { to 23) }\end{array}$} & \multicolumn{2}{|c|}{ Percentage } & \multicolumn{2}{|c|}{$\begin{array}{c}\text { Scale } \\
(0 \text { to } 23)\end{array}$} & \multicolumn{2}{|c|}{ Percentage } \\
\hline & $\mathbf{X}$ & SD & $\mathbf{X}$ & SD & $\mathbf{X}$ & SD & $\mathbf{X}$ & SD \\
\hline \multicolumn{9}{|l|}{ Gender } \\
\hline $\begin{array}{l}\text { Female } \\
(\mathrm{n}=8)\end{array}$ & 7.33 & 3.55 & 56.4 & 24.62 & $11.33^{*}$ & 2.20 & 77.7 & 16.95 \\
\hline $\begin{array}{l}\text { Male } \\
(\mathrm{n}=28)\end{array}$ & 8.37 & 1.70 & 64.38 & 10.90 & $13.66^{*}$ & 0.84 & 83.76 & 6.51 \\
\hline \multicolumn{9}{|l|}{ Age group } \\
\hline $\begin{array}{l}\text { Under-18 } \\
(\mathrm{n}=23)\end{array}$ & 8.39 & 1.52 & 64.54 & 11.76 & $10.30^{*}$ & 1.40 & 81.27 & 10.83 \\
\hline $\begin{array}{l}\text { Under-15 } \\
(\mathrm{n}=13)\end{array}$ & 7.61 & 2.66 & 58.57 & 20.48 & $10.91^{*}$ & 1.18 & 84.02 & 9.13 \\
\hline \multicolumn{9}{|l|}{ Modality } \\
\hline $\begin{array}{l}\text { Greco- } \\
\text { Roman } \\
(\mathrm{n}=15)\end{array}$ & 8.50 & 1.83 & 65.38 & 14.10 & $13.25^{*}$ & 0.79 & 85.3 & 6.09 \\
\hline $\begin{array}{l}\text { Freestyle } \\
(\mathrm{n}=21)\end{array}$ & 7.91 & 2.10 & 60.89 & 16.18 & $13.15^{*}$ & 1.50 & 80.76 & 11.56 \\
\hline
\end{tabular}

Legend: $p<.05$, indicates significant differences between the pre-test and the post-test.
Table 5. Degree of knowledge acquisition and athletes' opinion of the educational training sessions (values expressed in percentages).

\begin{tabular}{lcccc}
\hline & Session 1 & Session 2 & Session 3 & $\begin{array}{c}\text { Total } \\
\text { (average) }\end{array}$ \\
\hline Task & 86.3 & 85.80 & 67.28 & 79.8 \\
$\begin{array}{l}\text { Evaluation of the } \\
\text { sessions }\end{array}$ & 70.96 & 85.80 & 85.8 & 80.9 \\
Satisfaction & 78.12 & 96.87 & 96.87 & 90.62 \\
\hline
\end{tabular}

The opinions and perceptions of both coaches and wrestlers were collected from the open questionnaires and the interviews and three themes were extracted concerning the effect of the educational program: 1) assessment of the educational program; 2) level of implication in the program; and 3) future interventions and new ideas.

1) Assessment of the education program. Coaches reviewed the educational program as a positive and useful experience for the wrestlers. The athletes also considered the sessions satisfactory and useful. These ideas were expressed in the following way:

It's is really adequate and necessary in our sport, where there are a lot of topics and myths about loss weight that affect their [the athletes'] health now and in the future. [Coach \#1]

It is useful. You have explained and provided information about problems that other wrestlers do not view as important. [Athlete \#31]

Thank you. It has been really valuable and useful. [Athlete \#11]

2) Level of implication of wrestlers. It was difficult to involve the athletes in changing their weight loss patterns. Coaches commented on the problems of engaging wrestlers in these topics due to sport stereotypes.

Athletes come here as another part of the training... there is a sport culture around this topic. It will take a lot to change it in the athletes. [Coach \#1]

3) Future interventions and new ideas. The coaches proposed the need to incorporate the family and coaches in this type of training in the future.

For most of the athletes, it's the family who decides what the athlete eats. [Coach \#1]

\section{Discussion}

The aim of this study was to investigate the effect of a formative program concerning nutrition and weight control and its risks in under-18 wrestlers. The hypothesis of this research was that by providing knowledge to the wrestlers, their knowledge and their awareness of this topic will increase, forming an important first-step toward long-term changes. Regarding nutritional 
knowledge, the participants' initial knowledge was satisfactory $(>70 \%)$. However, after the intervention, their knowledge decreased (20\%). The reason this decline may be due to a lack of trust in their nutrition knowledge or a misleading comprehension of the issue. It seems that their nutritional knowledge was not established on a solid foundation; thus, they doubted this knowledge when they received new information or reviewed what they knew. One of the possible reasons for these results could be that the wrestlers acquired their knowledge through informal procedures, and when they received formal training, they doubted their previous knowledge. It must be considered that most under-18 wrestlers are not in charge of buying and preparing their food, so they are not the ones that always make the decisions in this regard.

These results differ from previous intervention studies, which were successful in increasing athletes' knowledge or habits. However, the samples of these studies were not athletes from sports in which they compete in different categories according to their weight. Other aspects of these interventions that were different include:(1) they were mostly conducted with female college athletes ${ }^{5,16,28},(2)$ the intervention was done as part of their team training 5 , (3) they provided individual information about their nutrition habits ${ }^{5,16,23,28}$, (4) the interventions were individualized $^{5,16,23},(5)$ there was a guided follow-up $p^{5,15,23},(6)$ they lasted a longer period of time $e^{5,15,23}$, and (7) all the athletes belonged to the same training group or team ${ }^{5}$. These differences show that the age of the group, the type of sport, gender, intervention duration, and individualization of the program are all important aspects to take into consideration when implementing this type of intervention. More information is needed about the evolution of the athletes regarding nutrition and weight control and its risks throughout the athletes' different developmental stages and the process through which the athletes build their knowledge.

The program was effective in relation to increasing knowledge of weight control and its risks. This result is likely due to the lower initial knowledge level recorded (approximately $50 \%$ ), which could be explained by the fact that the amount of informal information that players receive about weight control in comparison to basic nutrition may have been lower. The reason for this result could be that it was new knowledge for the athletes and it was perceived by them as appropriate, useful, and necessary. These results are similar to previous studies related to the positive effect of educational programs for preventing eating disorders ${ }^{15,29}$. The Junior National coaches also perceived the program as appropriate, useful, and necessary. However, they expressed their concern regarding the difficulty in changing sport stereotypes about weight control in this sport. Along these lines, although the athletes expressed their satisfaction and interest in the educational training, the athletes' coaches perceived that they did it as another piece of their training. These thoughts expressed by the coaches are supported by the athletes' low response rate in the re-test evaluation three months after the intervention program (when the wrestlers returned to their normal environment).

Future studies must be conducted to confirm the effect of educational programs in combat sports. These studies should involve athletes (in their normal environment), coaches, and families, and they should control the long-term effects of knowledge and habits regarding nutrition and weight control habits. The involvement of parents and coaches in this process is critical because they are the athlete's reference for habits and an important information source. Their comments, ways of acting, etc. affect the athletes' knowledge and habits. Ideally, the intervention program should be constant (during the athletes' sport-life), individualized, and include training in self-confidence. The goal of providing information is to provide athletes with the knowledge and skills to increase their wellness during and after the practice of their sport. Nevertheless, sport traditions are hard to change. In wrestling, some unhealthy behaviors are seen as normal by coaches and athletes. They perceive them as part of the process to prepare for competition. A uniform message is needed that stresses that this protocol must be considered as part of the old, unhealthy training style. Indeed, several studies have shown that these behaviors reduce the wrestler's physical and technical abilities to compete $\mathrm{e}^{30-32}$. If changes in mentality are not achieved through education, it will be hard to change these unhealthy patterns because they are seen as an inherent part of the sport.

\section{Conclusions}

The educational program was effective at increasing under-18 wrestlers' knowledge about weight control and its risk and was ineffective with regard to nutritional knowledge. The results show that under-18 wrestlers have no solid knowledge about nutrition, which highlights the need for providing information to athletes about aspects that affect their wellness. Longitudinal studies are needed to establish proper prevention protocols to implement with this population. These studies must be conducted in the athletes' normal training environment, and they should involve the athletes' coaches and families.

\section{References}

1. Artioli GG, Franchini E, Nicastro H, Sterkowick S, Solis MY, Lancha-Junior AH.. The need of a weight management control program in judo: A proposal based on the successful case of wrestling. J Int Soc Sports Nutr. 2010; 7: 15.

2. Oppliger RA, Steen SAN, Scott JR. Weight loss practices of college wrestlers. Int J Sport Nutr Exerc Metab. 2003; 13: 29-46.

3. Coutinho LAA, Porto CPM, Rocha-Pierucci APT. Critical evaluation of food intake and energy balance in Young modern pentathlon athletes: a cross- sectional study. J Int Soc Sports Nutr. 2016; 13(15).

4. Steen SN and Brownell KD. Patterns of weight-loss and regain in wrestlers: Has the tradition changed. Med Sci Sports Exerc. 1990; 22: 762-768.

5. Valliant MW, Emplaincourt HP, Wenzel RK, Garner BH. Nutrition education by a registered dietitian improves dietary intake and nutrition knowledge of a NCAA female volleyball team. Nutrients. 2012; 4: 506-516. 
6. Sundgot-Borgen J, Garthe I. Elite athletes in aesthetic and Olympic weight-class sports and the challenge of body weight and body compositions. J Sports Sci. 2011; 29(1): S101-14.

7. Artioli GG, Gualano B, Franchini E, Scagliusi FB, Takesian M, Fuchs $\mathrm{M}$ et all. Prevalence, magnitude, and methods of rapid weight loss among judo competitors. Med Sci Sports Exerc. 2010; 42:436-442.

8. Green CM, Petrou MJ, Fogarty-Hover MLS, Rolf CG. Injuries among judokas during competition. Scand J Med Sci Sports. 2007; 17:205-210.

9. Diaz I. Propuesta de un programa de prevención de trastornos de la conducta alimentaria para entrenadores. Cuad. psicol. Deporte. 2005; 5:1-2.

10. Hoogenboom BJ, Morris J, Morris C, Schaefer K. Nutritional knowledge and eating behaviors of female, collegiate swimmers. N Am J Sports Phys Ther. 2009; 4:139-48.

11. Amanat A, Al-Siyabi MS, Waly MI, Kilani HA. Assessment of nutritional knowledge, dietary habits and Nutrient intake of Univeristy student athletes. PJN. 2015; 14(5):293-299.

12. Bonci CM, Bonci LJ, Granger LR, Johnson CL, Malina RM, Milne LW et all. National athletic trainers' association position statement: Preventing, detecting, and managing disordered eating in athletes. J Athl Train. 2008; 43;80-108.

13. Gibbs AE, Pickerman J, Sekiya JK. Weight management in amateur wrestling. Sports Health. 2009; 1:227-230.

14. Kazemi M, Shearer H, Choung YS. Pre-competition habits and injuries in Taekwondo athletes. BMC Musculoskelet Disord. 2005; 6.

15. Ranby KW, Aiken LS, MacKinnon DP, Elliot DL, Moe EL, McGinnis W et all. A mediation analysis of the ATHENA intervention for female athletes: Prevention of athletic-enhancing substance use and unhealthy weight loss behaviors. J Pediatr Psychol. 2009; 34:1069-1083.

16. Abood DA, Black DK, Birnbaum RD. Nutrition education intervention for college female athletes. J Nutr Educ Behav. 2004, 36:135-139.

17. Bonci, L. Sport nutrition for coaches. Champaign, IL: Human Kinetics;2009.

18. Favaro A, Zanetti T, Huon G, Santonastaso P. Engaging teachers in an eating disorder preventive intervention. Int J Eat Disord. 2005; 38:73-77.

19. Zawila LG, Steib CSM, Hoogenboom B. The female collegiate cross-country runner: Nutritional knowledge and attitudes. J Athl Train. 2003, 38;67.

20. Folasire OF, Akomolafe AA, Sanusi RA. Does nutrition knowledge and practice of athletes translate to enhanced athletic performance? Cross-sectional study amongst Nigerian Undergraduate Athletes. Glob J Health Sci. 2015; 7 (5).

21. Alaunyte L, Perry JL, Aubrey T. Nutrition knowledge and eating habits of professional rugby league players: does knowledge translate into practice? J Int Soc Sports Nutr. 2015; 12:18
22. Bean A. Anita Bean's sports nutrition for young athletes. London 2010; A \& C Black Publishers Ltd.

23. Lagowska K, Kapczuk K, Friebe Z, Bajerska J. Effects of dietary intervention in young female athletes with menstrual disorders. J Int Soc Sports Nutr. 2014; 11(21).

24. Mielgo-Ayuso J, Collado P.S., Urdampilleta A et al. Changes induced by diet and nutritional intake in the lipid profile of female professional volleyball players after 11 weeks of training. J. Int. Soc. Sports. Nutr .2013; 10 (1), 55.

25. Miegol-Ayuso J, Zourdos MC, Calleja-Gonzalez, Urdampilleta A, Ostojic SM. Dietary intake habits and controlled training on body composition and strength in elite female volleyball players during the season. App. Physiol. Nutr. Metab. 2015; 40:1-8.

26. Juzwiak CR, Ancona-Lopez F. Evaluation of nutrition knowledge and dietary recommendations by coaches of adolescent Brazilian athletes. Int J Sport Nutr Exerc Metab. 2004; 14:222-235.

27. Bulger SM, Housner LD. Modified Delphi investigation of exercise science in physical education teacher education. J Teach Phys Educ. 2007; 26:57-80.

28. Kunkel ME, Bell LB, Luccia BHD. Peer nutrition education program to improve nutrition knowledge of female collegiate athletes. J Nutr Educ. 2001; 33:114-115.

29. Raymond-Barker P, Petroczi A, Quested E. Assessment of nutritional knowledge in female athletes susceptible to the Female Athlete Triad syndrome. J Occup Med Toxicol. (London, England). 2007; 2:10-10.

30. Franchini E, Brito CJ, Artioli GG. Weight loss in combat sports: physiological, psychological and performance effects. J Int Soc Sports Nutr. 2012; 9(1):1.

31. Moghaddami A, Gerek Z, Karimiasl A, Nozohouri H. The effect of acute dehydration and rehydration on biomechanical parameters of elite wrestling techniques. J Sport Sci. 2016; 4:93-101.

32. Pettersson S, Ekström, MP, Berg CM. Practices of weight regulation among elite athletes in combat sports: a matter of mental advantage?. J Athl Train. 2013; 48(1): 99-108.

\section{Corresponding author}

Andrea Visiedo

Email:andreavismero@gmail.com

Manuscript received on July 25, 2016

Manuscript accepted on October 18, 2016

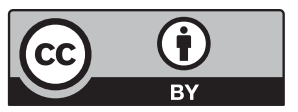

Motriz. The Journal of Physical Education. UNESP. Rio Claro, SP, Brazil - eISSN: 1980-6574 - under a license Creative Commons - Version 3.0 